\title{
Patterns of primary care among persons with schizophrenia: the role of patients, general practitioners and centre factors
}

\author{
Ma Carmen Castillejos Anguiano ${ }^{1 *}$ (E) Carlos Martín Pérez ${ }^{2}$, Antonio Bordallo Aragón ${ }^{3}$, Jesus Sepúlveda Muñoz ${ }^{4}$ \\ and Berta Moreno Küstner ${ }^{1}$
}

\begin{abstract}
Background: Patients with schizophrenia and related disorders have more physical problems than the general population. Primary care professionals play an important role in the care of these patients as they are the main entry point into the healthcare system. We aimed to identify patient, general practitioner, and primary care centre factors associated with the number of visits of patients with schizophrenia and related disorders to general practitioners.

Methods: A descriptive, cross-sectional study was conducted in 13 primary care centres belonging to the Clinical Management Unit of Mental Health of the Regional Hospital of Málaga, Spain. The eligible population was composed of patients with schizophrenia and related disorders attending the primary care centres in the study area, and the general practitioners who attend these patients. Our dependent variable was the total number of general practitioner visits made by patients with schizophrenia and related disorders during the 3.5-year observation period. The independent variables were grouped into three: (a) patient variables (sociodemographic and clinical), (b) general practitioner variables, and (c) primary care centre characteristics. Descriptive, bivariate, and multivariate analyses using the random forest method were performed.
\end{abstract}

Results: A total of 259 patients with schizophrenia and related disorders, 96 general practitioners, and 13 primary care centres were included. The annual mean was 3.9 visits per patient. The results showed that younger general practitioners, patients who were women, patients who were married, some primary care centres to which the patient belonged, taking antipsychotic medication, presenting any cardiovascular risk factor, and more frequency of mental health training sessions at the primary care centre were associated with an increased number of visits to general practitioners.

Conclusions: The only general practitioner variable that was associated with the number of visits was age, the older the less contact. There were also patient variables involved in the number of visits. Finally, mental health training for general practitioners was important for these professionals to manage patients with schizophrenia and related disorders.

Keywords: Primary health care, Schizophrenia, Use of services

*Correspondence: mccasang@gmail.com

1 Departament of Personality, Assessment and Psychological Treatment, Faculty of Psychology, Andalusian Group of Psychosocial Research (GAP), Biomedical Research Institute of Malaga (IBIMA), University of Malaga, Campus Teatinos, 29071 Malaga, Spain

Full list of author information is available at the end of the article

\section{Background}

Patients with schizophrenia have high levels of medical comorbidity and cardiovascular risk factors $[1,2]$. Thus, the lifespan of these patients with severe mental illness (SMI) is shorter compared to the general population [3]. This is due not only to their particular lifestyle [4-8] the original author(s) and the source, provide a link to the Creative Commons licence, and indicate if changes were made. The images or other third party material in this article are included in the article's Creative Commons licence, unless indicated otherwise in a credit line to the material. If material is not included in the article's Creative Commons licence and your intended use is not permitted by statutory regulation or exceeds the permitted use, you will need to obtain permission directly from the copyright holder. To view a copy of this licence, visit http://creativecommons.org/licenses/by/4.0/. The Creative Commons Public Domain Dedication waiver (http://creativeco mmons.org/publicdomain/zero/1.0/) applies to the data made available in this article, unless otherwise stated in a credit line to the data. 
but also to the antipsychotic medication they are taking [8-10].

Primary care has multiple benefits for patients in general and for patients with a complex chronic illness specifically, and a relationship has been demonstrated between availability of primary care and survival in patients with schizophrenia and related disorders (SRDs) [11]. However, the attention of these patients to their physical problems by primary care continues to be deficient. In previous work, it was found that patients with SRDs had significantly lower recorded rates of cardiovascular disorders $[12,13]$.

It seems that general practitioners (GPs) stigmatise mental illnesses more than psychiatrists when the attitudes of different categories of health professionals were compared [14-16]. This perception could influence their decisions in daily practice [17], which can be detected by patients [18]. In addition, feeling unprepared, having low confidence, and a lack of resources to manage mental illness from GPs $[19,20]$ could encourage GPs to transfer these patients to specialised care [21]. Both factors could explain the low contact of patients with SRDs with primary care services $[16,21,22]$. On the other hand, mental health professionals often do not feel confident in prescribing physical health medication [23]. However, it has been seen that when there was a collaborative work model between mental health and primary care services, GPs felt more confidence in managing patients with SMI [21], had fewer misperceptions of mental illness, and were less inclined to stigmatise it [24].

Therefore, the excess of mortality of patient with SRDs is due not only to their lifestyle and antipsychotic medication but also to poorer access to and quality of received health care, negative perceptions of people with SMI, and lack of awareness of increased cardiovascular risk in these patients by some health professionals $[3,25]$. Taking this into account and bearing in mind the important role of GPs as a main entry point into the healthcare system and as specialists in physical health problems, it is essential to study whether the characteristics of these professionals could influence the care of patients with SRDs. In a previous study, we analysed the association between patient factors and primary care centre (PCC) variables with the number of SRD patient visits to GPs [22], but we lacked an important link-the role of GP characteristics in the contact. Therefore, in the present study we aimed to identify patient, general practitioner, and primary care centre factors associated with the number of visits of patients with schizophrenia and related disorders to general practitioners.

\section{Methods}

An observational, cross-sectional study was conducted.

\section{Study area and temporal scope}

The study was carried out in the Community Mental Unit of Mental Health (CMU-MH) of the Regional Hospital of Málaga, with two Community Mental Health Units (CMHUs), Central and Northern, which together covered a population of 315,159 inhabitants. The Central CMHU included six PCCs: Alameda-Perchel, Victoria, Limonar, El Palo, Colmenar, and Rincón de la Victoria; and the Northern CMHU included seven PCCs: Trinidad, Nueva Málaga, Miraflores, Palma-Pamilla, CiudadJardín, Capuchinos, and Carlinda.

The study information was collected from January 1 , 2008 to July 1, 2011.

\section{Eligible population and sample Patients}

The eligible population was composed of the patients with SRDs included in the Málaga Schizophrenia Case Register (RESMA). The RESMA was a case register of patients with SRDs who were attending the CMU-MH Area Regional Hospital of Málaga to improve the care of patients with SMI [26].

The sample size was calculated to be representative of the patients of each PCC. Patients were selected with simple random sampling, stratified by PCC. Inclusion criteria were: (a) age over 14 years, (b) having a clinical diagnosis of SRD according to the ICD-10 before January 1 , 2008 , and (c) being in contact with a PCC in the coverage area of the CMU-MH of the Regional Hospital of Málaga. Exclusion criteria were: (a) being in treatment outside the study area, (b) having died during the follow-up, and (c) not having a computerized medical history in their reference PCC. In the present study only patients who had information about their GP were included $(\mathrm{N}=259)$. This is because one of our objectives was to analyse the GPs characteristics.

\section{General practitioners}

We obtained information from 96 GPs in total, all of whom worked in the study area and attended patients with schizophrenia included in our study.

\section{Study variables}

Our dependent variable was the total number of GP visits made by patients with SRD during the three-and-a-halfyear observation period.

The independent variables were grouped into three groups:

a) Patient variables. Sociodemographic: gender; marital status; educational level; living arrangements; employment status; type of area where they lived; whether they lived in a socioeconomically deprived 
area; primary care centre which they belonged to; and age. Clinical variables: ICD-10 clinical diagnosis; global level of severity; cardiovascular risk factors; and taking antipsychotic medication. (Additional file 1: Table S1).

b) GPs variables. Gender; specialization training as general practitioner; accredited training as a tutor; having any residential training students; age; time to complete the medical degree; size of patient list; relationship; training; and beliefs. (Additional file 1: Table S1).

We used the Primary Care Physicians and Mental Health Questionnaire (MAPSAM-14), which has been validated by the research team [27], to assess perceptions of GPs towards mental health. This instrument offers scores on the three MAPSAM-14 scales: (1) Relationship: the level of satisfaction of GP's relationship with the local CMHU (range: 7-15; higher scores indicated greater satisfaction with the relationship); (2) Beliefs: that touched upon erroneous beliefs, stigmas and attitudes about mental illness and stigmatisation of mental illness (range: 5-12; higher scores indicated more erroneous beliefs and greater stigmatisation); (3) Training: the GP's perception of the adequacy of his or her training in mental health, including schizophrenia and related disorders (range: 5-15; higher scores indicated greater perceived adequacy of training).

c) Primary care centre variables: hometown; frequency of mental health care visits; frequency of mental health training session; training from mental health services; active role of GPs, nurses and social workers; and level of communication between primary care centre and community mental health centre, as well as level of communication between GPs and nurses; and communication between GPs and social workers (Additional file 1: Table S1)."

\section{Data sources}

Data on the total number of GP visits were obtained from digitised primary care records (DIRAYA program). Sociodemographic and clinical information about patients was obtained from RESMA [26, 28]. Information about the PCCs was collected from their directors, who were interviewed using a questionnaire designed by the research team of this study. Finally, GPs filled in another questionnaire also designed by the research team [28].

\section{Data analysis}

The categorical variables used in the descriptive analysis were frequency distribution and percentages. Descriptive statistics (mean, standard deviation, and median) were calculated for the continuous variables.

We used a bivariate analysis to examine the relationships between the dependent (number of GP visits) and independent (predictive) variables. For categorical variables with two categories, the Wilcoxon test was used, and for categorical variables with more than two categories, the Kruskal-Wallis test was used. Finally, for continuous explanatory variables, Spearman's correlation coefficient was calculated. Differences were considered significant at $\mathrm{p}<0.05$.

The classic multivariate analysis (linear regression) is hindered by the large number of predictor variables in relation to the relatively small sample size of the study. We used the random forest technique to solve this problem.

Random forest (RF) is one of the so-called ensemble methods for predictive regression models, which is based on the methodology of classification and regression trees (CART). With the RF procedure, a large group of trees is generated in which each tree predicts the result of the dependent variable. In the process of constructing the set of trees, RF uses two types of randomization. First, each tree is constructed using a subsample of the database. The size is approximately two-thirds of the initial sample. In addition, a second level of randomness is added by selecting for each tree a random sample of the predictive variables in each node to choose the best division.

The number of predictors selected in each node and the total number of trees that are built are the two main parameters of the RF algorithm. A third parameter is the minimum size of each node terminal.

As a result of the use of a subsample of training data, about one-third of the samples are omitted when building each tree. These are the so-called out-of-bag samples (OOB), which can be used to evaluate the prediction error and to construct measures of importance of the predictive variables.

We used the permutation index of importance to evaluate the importance of the predictive variables. The importance of a variable was assessed by estimating the change in the prediction error that occurs when, in the OOB data, the variable is randomly swapped while the others remain unchanged. The calculations were made tree-by-tree as the random forest was constructed. If a variable was important in the problem analysed, changing its random values led to larger changes in the prediction adjustment compared to those variables that were not important.

The variables to be included in the model were selected so that it explained the highest percentage of the variability with respect to the result, assuming the least possible prediction error. To do this selection, the VSURF package 
in the R software was used, which followed a two-step strategy. First, the variables of the initial model (all) were classified according to their importance, and those that did not exceed a threshold were eliminated, which was determined based on the standard deviation of that importance. In a second step, with the variables selected in the previous step, a series of nested RF models were built, and the one that generated a lower OOB error was selected. The variables selected will be important and will have a strong relationship with the dependent variable.

For missing data that did not exceed $15 \%$ of the total data of the variable, the miss forest package in $\mathrm{R}$ was used, which can be used to impute continuous and/or categorical data including complex interactions and nonlinear relationships. Variables presenting more than $15 \%$ of missing data were eliminated.

We used the Random Forest $\mathrm{R}$ package and its default parameters, and then these hyper parameters were tuned to obtain the least possible error.

The statistical package $\mathrm{R}$ was used for the statistical analysis.

\section{Results}

Of the total sample of 494 patients included in the study carried out by Castillejos et al. [22], 259 were included. Therefore, the total sample in the present study consisted of 259 patients and 96 GPs. Regarding the patients included, the sociodemographic profile was as follows. The mean age at the beginning of the study was 43.88 years (range: $22-80$ ); $63.71 \%$ were male; $70.66 \%$ were single; $43.63 \%$ completed only primary school; $55.21 \%$ were living with their original family or other relatives; $37.84 \%$ were unable to work; $88.03 \%$ were living in urban areas; and $89.19 \%$ were living in non-socioeconomically-deprived areas. Most patients had a clinical diagnosis of schizophrenia (69.5\%), 82.24\% of whom had a low or medium global level of severity, $39.23 \%$ had at least one cardiovascular risk factor (type 2 diabetes mellitus, hypertension, hypercholesterolaemia, obesity and smoking), and $69.11 \%$ were taking antipsychotic medication (see Table 1).

Regarding characteristics of GPs, the mean age at the beginning of the study was 50.84 years old (range: $38-63)$, 63.54\% were women, about $50 \%$ had specialised training as a GP, $65.62 \%$ were not accredited training as a tutor, $63.16 \%$ had a residential training student, and $87.5 \%$ had training from mental health services. Moreover, it took 4-11 years to finish their medical degree. The size of the patient list varied from 900 to 2,434 patients per GP. Regarding the perception of GPs on mental illness, they presented high punctuation in the level of satisfaction with their relationship with the community mental health centre, medium punctuation in the perception of their level of training in mental health, schizophrenia, and other psychotic disorders, and very low punctuation in erroneous beliefs and stigmatisation about mental illness (see Table 2).

With respect to PCC variables, $69.2 \%$ of the directors of the PCCs agreed that PCCs received assistance visits from mental health services more than twice a month, and $46.2 \%$ of them agreed that PCCs received training sessions from mental health services once a month or more. Most of the directors (76.9\%) agreed that there was training from mental health services to PCCs. In addition, most of the directors agreed that social workers $(69.3 \%)$ play an active role in managing patients' mental health, but nevertheless, 53.9 and $36.46 \%$ of them agreed with this role in GPs and nurses, respectively. Regarding communication between the PCC and community mental health centre, almost all directors interviewed (92.71\%) agreed with it was good or very good. All of them agreed with the good communication between GPs and nurses, and 69.3\% agreed with the good communication between GPs and social workers (see Table 3).

The mean number of patient contacts with their GPs during the study period was 13.53 (median $=11$; range: 0-69). The annual mean was 3.9 visits per patient.

The bivariate analysis showed that the patient factors associated with more contact with GPs were: being a woman $(\mathrm{p} \leq 0.001)$, being married or with a partner $(\mathrm{p}=0.0038)$, having no formal education $(\mathrm{p}=0.011)$, having a schizoaffective disorder diagnosis $(p=0.0213)$, having any cardiovascular risk factor $(\mathrm{p} \leq 0.001)$, and taking antipsychotic medication ( $\mathrm{p}=0.0011$; see Tables 4 and 5).

In addition, the GP factors that were clearly associated with more contact with GPs were as follows: GP age was negatively associated, as older GPs were associated with less contact $(\mathrm{p} \leq 0.001)$; and the training variables were also positively associated, such that GPs who had a perception of higher level of training in mental health received more contact $(\mathrm{p}=0.0219$; see Table 6$)$.

Lastly, there were statistically significant differences among the PCCs to which patients attended $(\mathrm{p}=0.02)$. Colmenar (with a mean contact of 33), Trinidad (17.8), El Palo (17.5), and Carlinda (15) were the PCCs that presented more visits to the GPs (see Table 6). There were others PCC factors that almost reached statistical significance: GP and nurse roles in managing patients' mental health, such that higher punctuation in GP role was positively associated with amount of contact $(p=0.053)$, but higher punctuation in nurse role was negatively associated $(\mathrm{p}=0.0589)$; and communication between GPs and social workers was positively associated with amount of contact with GPs $(\mathrm{p}=0.0508$; see Additional file 2: Table S2). 
Table 1 Characteristics of patients with schizophrenia and related disorders

Sociodemographic characteristics

Gender

Male

Female

Marital status

Single

Married/civil partnership/cohabiting

Separated/divorced/widowed

Educational level

No formal education and/or illiterate

Primary school

Secondary school

Higher education (Bachelor's degree)

Living arrangements

Alone

Original family/other relatives or friends

Own family

Sheltered accommodation

Homeless

Employment status

Employed

Unemployed

Student

Carer or househusband/housewife

Not working, receiving welfare benefits

Other

Type of area

Urban

Rural

Within a socioeconomically deprived area

No

Yes

Primary care centre

Trinidad

Nueva Málaga

Miraflores

Palma-Palmilla

Ciudad Jardín

Capuchinos

Carlinda

Alameda Perchel

Victoria

Limonar

El Palo

Rincón de la Victoria

Colmenar

Clinical characteristics

ICD-10 Clinical diagnosis

F20 Schizophrenia
Patients N (\%)

$165(63.71 \%)$

94 (36.29\%)

$183(70.66 \%)$

$47(18.15 \%)$

$29(11.2 \%)$

45 (17.37\%)

$113(43.63 \%)$

72 (27.8\%)

$29(11.2 \%)$

$33(12.74 \%)$

143 (55.21\%)

57 (22.01\%)

$23(8.88 \%)$

$3(1.16 \%)$

$46(17.76 \%)$

49 (18.92\%)

$16(6.18 \%)$

$14(5.41 \%)$

98 (37.84\%)

36 (13.9\%)

228 (88.03\%)

31 (11.97\%)

231 (89.19\%)

28 (10.81\%)

$21(8.11 \%)$

$7(2.7 \%)$

$10(3.86 \%)$

17 (6.56\%)

25 (9.65\%)

8 (3.09\%)

$3(1.16 \%)$

26 (10.04\%)

$33(12.74 \%)$

$30(11.58 \%)$

$50(19.31 \%)$

$28(10.81 \%)$

$1(0.39 \%)$

$26(10.04 \%)$ 
Table 1 (continued)

\begin{tabular}{lc}
\hline Sociodemographic characteristics & Patients N (\%) \\
\hline F23 Acute and transient psychotic disorders & $25(9.65 \%)$ \\
F25 Schizoaffective disorders & $17(6.56 \%)$ \\
F21, F24, F28, F29 Schizotypal disorder, Induced delusional disorder, other non-organic psychotic disorders and unspecified non- & 11 (4.25\%) \\
$\quad$ organic psychosis & \\
Global level of severity & $91(35.14 \%)$ \\
$\quad$ Level I (low severity) & $122(47.1 \%)$ \\
Level II & $46(17.76 \%)$ \\
Level III (high severity) & $156(60.23 \%)$ \\
Cardiovascular risk factors & $103(39.77 \%)$ \\
$\quad$ No & \\
Yes & $80(30.89 \%)$ \\
Taking antipsychotic medication & $179(69.11 \%)$ \\
No & $259(100 \%)$ \\
Yes &
\end{tabular}

Categorical variables $(\mathrm{N}=259)$

Table 2 Characteristics of general practitioners $(N=96)$

\begin{tabular}{|c|c|c|c|c|c|}
\hline Variable & $\mathrm{N}(\%)$ & Minimum & Maximum & Mean & Median \\
\hline \multicolumn{6}{|l|}{ Gender } \\
\hline Male & $35(36.46 \%)$ & & & & \\
\hline Female & $61(63.54 \%)$ & & & & \\
\hline \multicolumn{6}{|c|}{ Specialisation training as a General Practitioner (GP) } \\
\hline Yes & $53(56.38 \%)$ & & & & \\
\hline No & $41(43.62 \%)$ & & & & \\
\hline \multicolumn{6}{|c|}{ Accredited training as a tutor } \\
\hline Yes & $33(34.38 \%)$ & & & & \\
\hline No & $63(65.62 \%)$ & & & & \\
\hline \multicolumn{6}{|c|}{ Having any residential training student } \\
\hline Yes & $60(63.16 \%)$ & & & & \\
\hline No & $35(36.84 \%)$ & & & & \\
\hline Age & & 38 & 63 & 50.84 & 52 \\
\hline $\begin{array}{l}\text { Time to } \\
\text { complete } \\
\text { the medical } \\
\text { degree }\end{array}$ & & 4 & 11 & 7.49 & 7 \\
\hline $\begin{array}{l}\text { Size of patient } \\
\text { list }\end{array}$ & & 900 & 2434 & 1603 & 1500 \\
\hline Relationship ${ }^{\mathrm{a}}$ & & 7 & 15 & 12.71 & 13 \\
\hline Training ${ }^{b}$ & & 4 & 11 & 8.1 & 8 \\
\hline Beliefs $^{c}$ & & 4 & 10 & 5.05 & 4 \\
\hline
\end{tabular}

a Level of satisfaction of GPs with their relationship with the community mental health centre

b The GPs' perception of their level of training in mental health, schizophrenia and other psychotic disorders

c Erroneous beliefs, stigmas and attitudes regarding mental illness
Regarding the multivariate analysis, based on the method explained previously in the data analysis, we achieved the model with the lowest OOB error with seven variables (see Fig. 1). Therefore, younger general practitioners, patients who were women, patients who were married, some primary care centres to which the patient belonged, taking antipsychotic medication, presenting any cardiovascular risk factor, and more frequency of mental health training sessions at the primary care centre were strongly associated with an increase in the number of visits to GPs in the multivariate analysis (see Fig. 2).

\section{Discussion}

In a previous study carried out by our research group, we analysed the relationship between patients with SRD/ PCC characteristics and the number of visits to GPs [22]. The novelty of the present study is in the association of characteristics of the GPs who treated these patients with the amount of contact with GPs, which led to important findings. GP age, patient gender, patient marital status, PCC to which the patient belonged, taking antipsychotic medication, presenting any cardiovascular risk factor, and frequency of mental health training visits to the PCC were associated with an increased number of visits to GPs. In addition, a novel statistical analysis technique based on the random forest method was used to perform a multivariate analysis.

With the subsample analysed, the mean annual number of visits to GPs during the observation period was similar to that found with the entire sample analysed and discussed in the previous study [22]. 
Table 3 Primary care centre variables $\mathrm{N}=13$

Hometown

2,500-5,000 inhabitants

$1(7.7 \%)$

5,000-10,000 inhabitants

$1(7.7 \%)$

10,000-15,000 inhabitants

$1(7.7 \%)$

15,000-20,000 inhabitants

$1(7.7 \%)$

20,000-30,000 inhabitants

$6(46 \%)$

More than 30,000 inhabitants

$3(23.1 \%)$

Frequency of mental health care visits in primary care centres

Twice a month

$4(30.8 \%)$

More than twice a month

9(69.2\%)

Frequency of mental health training sessions in primary care centres

None

$3(13.23 .1 \%)$

Once a year or less

$1(7.7 \%)$

Between 4 and 6 months

$1(7.7 \%)$

Every 2 months

$2(15.4 \%)$

Once a month

$4(30.8 \%)$

Twice a month

$1(7.7 \%)$

More than twice a month

$1(7.7 \%)$

Training from mental health services

Yes

No

Primary care physician active role in managing patients' mental health

Neither agree nor disagree

Agree

Completely agree

Nurse active role in managing patients' mental health

Completely disagree

Neither agree nor disagree

$7(53.8 \%)$

Agree

Completely agree

Social worker active role in managing patients' mental health

Disagree

Neither agree nor disagree

$2(15.4 \%)$

Agree

$4(30.8 \%)$

Completely agree

$5(38.5 \%)$

Level of communication between the primary care centre and community mental health centre

Very goodW

Level of communication between primary care physicians and nurses

Good

Very good

Level of communication between primary care physicians and social workers

Neither good nor bad

Good 
Table 4 Bivariate analysis between dichotomous variables and number of contact with general practitioners

\begin{tabular}{lll}
\hline & W Wilconxon & P value \\
\hline Patient gender & 10,172 & $\leq 0.001$ \\
Cardiovascular risk factors & 5380 & $\leq 0.001$ \\
Taking antipsychotic medication & 5352 & 0.0011 \\
Type of area & 4005.5 & 0.2284 \\
Within a socioeconomically deprived are & 3005 & 0.5413 \\
General Practitioner gender & 8797.5 & 0.0720 \\
Specialisation training as a General Practitioner & 9216.5 & 0.0718 \\
Accredited training as a tutor & 8662.5 & 0.0653 \\
Having any residential training student & 8697 & 0.1118 \\
Training from mental health services & 3166 & 0.1055 \\
Level of communication between primary & 2343 & 0.8850 \\
care physicians and nurses & &
\end{tabular}

The variable that was most associated with the number of visits was GP age, such that older GPs had less contact with patients. This could be related to older GPs having a more negative attitude toward patients with schizophrenia than their younger counterparts [29], although not all studies have found this result $[24,30]$.

Women visited GPs more often, which is in line with other studies [11, 31, 32].

Patient marital status was also related to the number of visits to GPs, so that patients who were married or living with a partner visited GPs more than single patients. This could be because family support causes these patients to receive continued care. We also found that patients who were separated, divorced, or widowed made more visits to their GPs than single patients. Copeland et al.
Table 6 Bivariate analysis between continuous variables and number of contact with general practitioners

\begin{tabular}{lrl}
\hline & \multicolumn{1}{c}{$\boldsymbol{\rho}$} & p value \\
\hline Patient age & 0.098 & 0.1162 \\
General practitioner age & -0.247 & $\leq 0.001$ \\
Time to complete the Medical degree & 0.058 & 0.3504 \\
Size of patient list & -0.060 & 0.3610 \\
Relationship & 0.053 & 0.3945 \\
Training & 0.124 & 0.0219 \\
Beliefs & -0.111 & 0.0740 \\
\hline
\end{tabular}

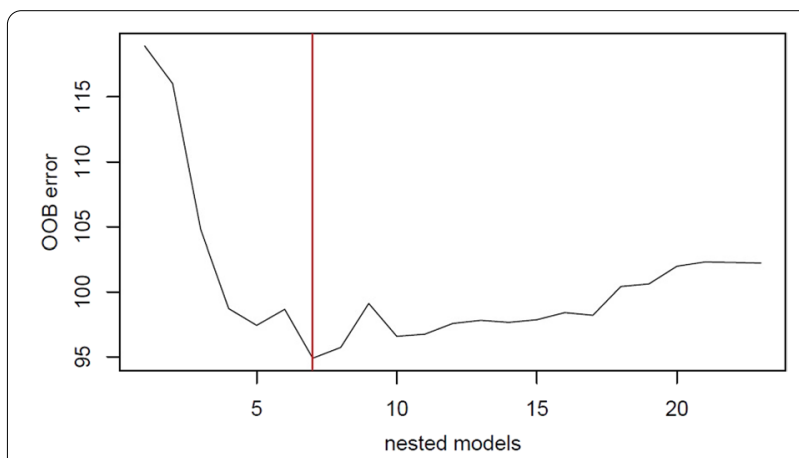

Fig. $1 \mathrm{OOB}$ error variation depending on the different nested models

[11] found that the number of visits to GPs by married patients or those with a partner was greater, but no greater number of these visits was found in patients who were separated, divorced, or widowed.

Table 5 Bivariate analysis between categorical variables with more than two categories and number of contact with general practitioners

\begin{tabular}{|c|c|c|c|}
\hline & Chi squared & df & $P$ value \\
\hline Patient marital status & 11.11 & 2 & 0.0038 \\
\hline Patient educational level & 11.246 & 3 & 0.0110 \\
\hline Patient living arrangements & 4.650 & 4 & 0.3251 \\
\hline Patient employment status & 5.446 & 5 & 0.3639 \\
\hline Primary care centre & 24.036 & 12 & 0.0201 \\
\hline ICD-10 Clinical diagnosis & 11.518 & 4 & 0.0213 \\
\hline Global level of severity & 0.689 & 2 & 0.7086 \\
\hline Hometown & 4.6082 & 5 & 0.4655 \\
\hline Primary care physician active role in managing patients' mental health & 5.874 & 2 & 0.0530 \\
\hline Nurse active role in managing patients' mental health & 7.446 & 3 & 0.0589 \\
\hline Social worker active role in managing patients' mental health & 6.760 & 4 & 0.1491 \\
\hline $\begin{array}{l}\text { Level of communication between the primary care centre and community mental health } \\
\text { centre }\end{array}$ & 4.490 & 2 & 0.1059 \\
\hline Level of communication between primary care physicians and social workers & 7.778 & 2 & 0.0508 \\
\hline
\end{tabular}



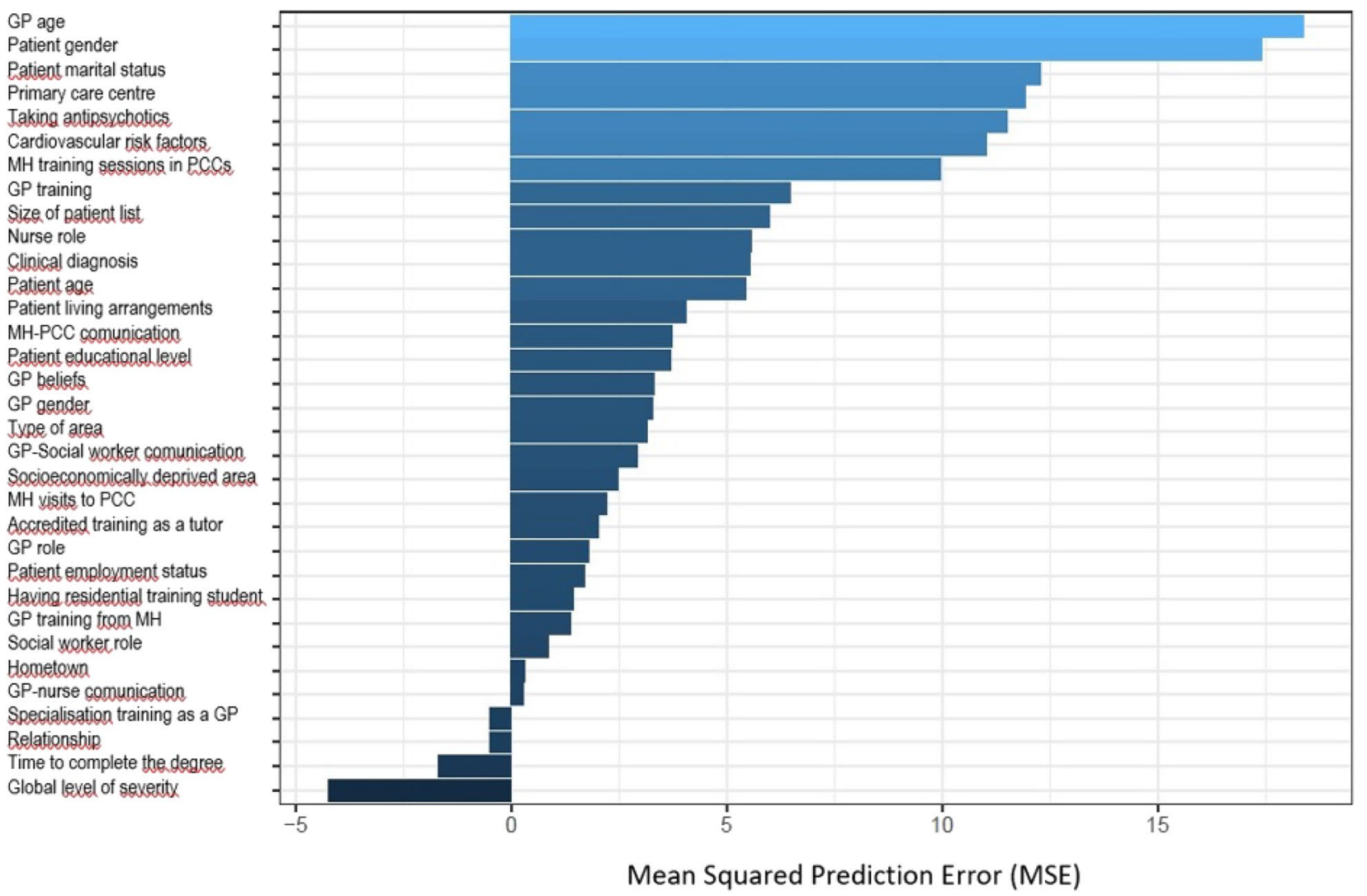

Fig. 2 Mean Square Prediction Error depending on the importance by permutation of the variables of the initial model. GP general practitioner, $M H$ mental health, PCC Primary Care Centre

The fourth variable that was more related to contact with GPs was the PCC to which patients belonged. In a previous study performed by our group, we found that GPs working at PCCs in the catchment area of Central CMHU had less stigma about mental illness, coinciding with the fact that this area had been working collaboratively with mental health services for 15 years [24]. However, in this study we found that the PCCs that received the highest number of visits to GPs belonged to both Central and Northern CMHU. These two facts seem to indicate that the stigma presented by GPs toward mental illness was not related to the number of visits they received from patients with SRDs. In addition, working in a collaborative model was not related to the increase in contact with GPs, which is in line with the results found in a previous study in which good communication between primary care and mental health services did not translate into increased contact, and this might be due to mental health professionals assuming some of the functions that otherwise would have been performed by the GPs [24].

Moreover, taking antipsychotic medication and presenting cardiovascular risk factors were also associated with a higher number of visits to GPs. On one hand, the fact that GPs are the health professionals in charge of the follow-up with diseases such as cardiovascular risk factors mean that patients with SRDs who present these problems visit their GP more than those who do not present them. On the other hand, GPs are also in charge of the follow-up in prescribing medication, hence both patients taking antipsychotic medication and those with cardiovascular risk factors (who usually also take medication for this disease) visit their GPs more frequently.

Finally, higher frequency of mental health training visits to the PCC resulted in more visits to the GP. Related to this is that, in the bivariate analysis, GP perception of higher level of training in mental health received more contact. These results are in line with the study carried out by Bagayogo et al. [20], who found that GP felt low confidence in treating complex mental health problems and the need to integrate mental health into primary care. Moreover, it was also found that when there was a collaborative work model between mental health and primary care services, GPs felt more confidence in managing patients with severe mental illness [21]. Therefore, it seems that a collaborative work model between mental 
health and primary care services at the training level can make GPs feel more capable of managing these patient problems and refer less to specialised services.

\section{Strengths and limitations}

- This study analysed multiple associations between patient, PCC, and GP characteristics and the number of visits by SRD patients to GPs.

- The study was carried out in a wide catchment area, including the participation of 13 PCCs.

- We analysed a large, homogeneous sample of patients diagnosed with SRDs living in the community.

- We performed a multivariate analysis using a novel statistical analysis technique based on the random forest method.

- For unknown reasons, not all GPs in the study area participated, and in some cases, the number of GPs per centre was very low. However, in general, the participation rate was high.

- This was a cross-sectional study from which we cannot infer causality but only association.

- Clinical diagnoses were not made through clinical interviews but rather by the patients' long-term psychiatrists and updated in the RESMA database.

- Information about patients was collected from medical records instead of specific health screening tests of individual patients.

\section{Conclusions}

This study analysed multiple associations between patient, GP, and PCC characteristics and the number of visits by SRD patients to GPs. It was surprising that the only GP characteristic that was clearly associated with the number of visits was GP age. It was confirmed that there were patient variables involved in the number of visits, such as gender and marital status. Finally, it was shown that the training of GPs is important for these professionals to manage patients with SRDs. Therefore, a collaborative model between mental health and primary care services should be promoted at the training level.

\section{Supplementary information}

Supplementary information accompanies this paper at https://doi. org/10.1186/s13033-020-00409-z.

Additional file 1: Table S1. Study variables.

Additional file 2: Table S2. Categorical variables associated with the number of visits to general practitioners.

\section{Abbreviations}

CART: Classification and regression trees; Cl: Confidence Interval; CMU-MH: Clinical Management Unit of Mental Health; CVRF: Cardiovascular Risk Factors;
GLS: Global Level of Severity; GP: General Practitioner; ICD: International Classification of Diseases; OOB: Out of bag; PCC: Primary Care Centre; RESMA Malaga Schizophrenia Case Register; RF: Random forest; SMI: Severe mental illness; SRD: Schizophrenia and related disorders.

\section{Acknowledgements}

The authors acknowledge the Primary Care District of Malaga, particularly Maximiliano Vilaseca and Francisco Javier Navarro for their support. We are also grateful to the directors and general practitioners at all the general practices who participated in this study. Finally, we thank Santiago Galan for his assistance with information collection.

\section{Authors' contributions}

Authors BMK, ABA and JSM designed the study and wrote the protocol. Author MCA managed the literature searches, analyses and wrote the first draft of the manuscript. CMP undertook the statistical analysis. All authors contributed to the final manuscript. All authors read and approved the final manuscript.

\section{Funding}

This study has been funded by Instituto Carlos III through the project PI16/00647 (Co-funded by European Regional Development Fund European Social Fund "A way to make Europa"/Investing in the future.

\section{Availability of data and material}

The data that support the findings of this study are available from Berta Moreno Küstner but restrictions apply to the availability of these data, which were used under license for the current study, and so are not publicly available. Data are however available from the authors upon reasonable request and with permission of Berta Moreno Küstner.

Ethics approval and consent to participate

The study was approved by the Health Research Ethics Committee of the Health District of Malaga.

\section{Consent for publication}

Not required.

\section{Competing interests}

None.

\section{Author details \\ ${ }^{1}$ Departament of Personality, Assessment and Psychological Treatment, Faculty of Psychology, Andalusian Group of Psychosocial Research (GAP), Biomedical Research Institute of Malaga (IBIMA), University of Malaga, Campus Teatinos, 29071 Malaga, Spain. ${ }^{2}$ Clinical Management Unit At Marquesado, Andalusian Health Service, Carretera Los Pozos, North East Granada Sanitary District, 18518 AlquifeGranada, Spain. ${ }^{3}$ Clinical Management Unit of Mental Health of the Regional Hospital of Malaga, Andalusian Health Service, Paseo Limonar, Malaga, Spain. ${ }^{4}$ Alameda-Perchel Basic Primary Care Team, Health District Malaga-Guadalhorce, Andalusian Health Service, Avenida Manuel Agustín Heredia, Malaga, Spain.}

Received: 18 August 2020 Accepted: 26 October 2020

Published online: 10 November 2020

\section{References}

1. Mitchell AJ, Vancampfort D, Sweers K, van Winkel R, Yu W, De Hert M. Prevalence of metabolic syndrome and metabolic abnormalities in schizophrenia and related disorders - a systematic review and metaanalysis. Schizophr Bull. 2013;39(2):306-18.

2. Eskelinen S, Sailas E, Joutsenniemi K, Holi M, Koskela TH, Suvisaari J. Multiple physical healthcare needs among outpatients with schizophrenia: Findings from a health examination study. Nord J Psychiatry. 2017;71(6):448-54. https://doi.org/10.1080/08039488.2017.1319497.

3. De Hert M, Dekker JM, Wood D, Kahl KG, Holt RI, Möller HJ. Physical illness in patients with severe mental disorders. I. Prevalence, impact of medications and disparities in health care. World Psychiatry. 2011;10(1):52-77. 
4. Bernardo M, Cañas F, Banegas JR, Casademont J, Riesgo Y, Varela C, on behalf of the RICAVA Study group. Prevalence and awareness of cardiovascular risk factors in patients with schizophrenia: a cross-sectional study in a low cardiovascular disease risk geographical area. Eur Psychiatry. 2009;24(7):431-41.

5. Deighton S, Addington J. Exercise practices in individuals at clinical high risk of developing psychosis. Early Interv Psychiatry. 2015:9(4):284-91.

6. Heald A, Pendlebury J, Anderson S, Narayan V, Guy M, Gibson M, et al. Lifestyle factors and the metabolic syndrome in Schizophrenia: a crosssectional study. Ann Gen Psychiatry. 2017;16:12.

7. Jahrami HA, Faris MAE, Saif ZQ, Hammad LH. Assessing dietary and lifestyle risk factors and their associations with disease comorbidities among patients with schizophrenia: a case-control study from Bahrain. Asian J Psychiatr. 2017;28:115-23.

8. Eskelinen S, Sailas E, Joutsenniemi K, Holi M, Suvisaari J. Clozapine use and sedentary lifestyle as determinants of metabolic syndrome in outpatients with schizophrenia. Nord J Psychiatry. 2015;69(5):339-45. https:// doi.org/10.3109/08039488.2014.983544.

9. Halpert S, McFarlane SI. When the heart and the mind collide: cardiovascular risk factors and antipsychotic use in the schizophrenic population. $J$ CadiometabSynd. 2009;4(1):1-5.

10. Rummel-Kluge C, Komossa K, Schwarz S, Hunger H, Schmid F, Lobos CA, et al. Head-to-head comparisons of metabolic side effects of second generation antipsychotics in the treatment of schizophrenia: a systematic review and meta-analysis. Schizophr Res. 2010;123(2-3):225-33.

11. Copeland LA, Zeber JE, Wang CP, Parchman ML, Lawrence VA, Valenstein $M$, et al. Patterns of primary care and mortality among patients with schizophrenia or diabetes: a cluster analysis approach to the retrospective study of healthcare utilization. BMC Health Serv Res. 2009;9:127.

12. Smith DJ, Langan J, McLean G, Guthrie B, Mercer SW. Schizophrenia is associated with excess multiple physical-health comorbidities but low levels of recorded cardiovascular disease in primary care: cross-sectional study. BMJ Open. 2013. https://doi.org/10.1136/bmjopen-2013-002808.

13. Woodhead C, Ashworth M, Broadbent M, Callard F, Hotopf M, Schofield $P$, et al. Cardiovascular disease treatment among patients with severe mental illness: a data linkage study between primary and secondary care. Br J Gen Pract. 2016;66(647):e374-81.

14. Hori H, Richards M, Kawamoto Y, Kunugi H. Attitudes toward schizophrenia in the general population, psychiatric staff, physicians, and psychiatrists: a web-based survey in Japan. Psychiatr Res. 2011;186(2-3):183-9.

15. Mittal D, Corrigan P, Sherman M, Chekuri L, Han X, Reaves C, et al. Healthcare providers' attitudes toward persons with schizophrenia. PsychiatrRehabil J. 2014;37(4):297-303.

16. Smith JD, Mittal D, Chekuri L, Han X, Sullivan G. A Comparison of provider attitudes toward serious mental illness across different health care disciplines. Stigma Health. 2017;2(4):327-37.

17. Corrigan PW, Mittal D, Reaves CM, Haynes TF, Han X, Morris S, et al. Mental health stigma and primary health care decisions. Psychiatr Res. 2014;218(1-2):35-8.

18. Cabassa LJ, Gomes AP, Meyreles Q, Capitelli L, Younge R, Dragatsi D, et al Primary health care experiences of hispanics with serious mental illness: a mixed-methods study. Adm Policy Ment Health. 2014;41:724-36.

19. Caplan S, Little TV, Garces-King J. Stigma about mental illness among multidisciplinary health care providers in the Dominican Republic. Perspect Psychol Sci. 2016;5(3):192-206.
20. Bagayogo IP, Turcios-Wiswe K, Kanako T, Peccoralo L, Katz CL. Providing Mental health services in the primary care setting: the experiences and perceptions of general practitioners at a New York City Clinic. Psychiatric Q. 2018;89(4):897-908.

21. Fleury MJ, Bamvita JM, Tremblay J. Variables associated with general practitioners taking on serious mental disorder patients. BMC FamPract. 2009:10:41. https://doi.org/10.1186/1471-2296-10-41.

22. Castillejos MC, Martín-Pérez C, Mayoral-Cleries F, Bordallo-Aragón A, Sepúlveda- Muñoz J, Moreno-Küstner B. Factors associated with visits to general practitioners in patients with schizophrenia in Malaga. BMC Fam Pract. 2018;19:180. https://doi.org/10.1186/s12875-018-0866-7.

23. Mitchell AJ, Lord O, Malone D. Differences in the prescribing of medication for physical disorders in individuals with v. without mental illness: meta-analysis. Br J Psychiatry. 2012;201:435-43.

24. Castillejos-Anguiano MC, Bordallo-Aragón A, Aguilera-Fernández D, Moreno-Küstner B. Perceptions about mental illness among genera practitioners. Int J Ment Health Syst. 2019. https://doi.org/10.1186/s1303 3-019-0284-9.

25. Burton A, Osborn D, Atkins L, Michie S, Gray B, Stevenson F, et al. Lowering cardiovascular disease risk for people with severe mental illnesses in primary care: a focus group study. PLoS ONE. 2015;10(8):e0136603. https ://doi.org/10.1371/journal.pone.0136603.

26. Moreno-Küstner B, Mayoral F, Pérez O, García-Herrera JM, Algarra J, Rivas F, et al. The Malaga schizophrenia case-register (RESMA): overview of methodology and patient cohort. Int J Soc Psychiatry. 2009;55(1):5-15.

27. Moreno-Küstner B, Bordallo-Aragon A, Sepúlveda-Muñoz J. Psychometrics properties of a questionnaire on the attitudes of general practitioners towards mental health (MAPSAM-14). An Psicol-Spain. 2018;34(2):258-63.

28. Moreno-Küstner B, Mayoral F, Navas-Campaña D, García-Herrera JM Angona P, Martín C, et al. Prevalence of schizophrenia and related disorders in Malaga (Spain): results using multiple clinical databases. Epidemiol Psychiatr Sci. 2016;25:38-48.

29. Rojas-Vistorte AO, Silva-Ribeiro W, Jaen D, Jorge MR, Evans-Lacko S, de Jesus MJ. Stigmatizing attitudes of primary care professionals towards people with mental disorders: a systematic review. Int J Psychiatry Med. 2018;53(4):317-38

30. Arbanas G, Rožman J, Bagarić Š. The attitudes of medical doctors, nurses and lay people towards schizophrenia, depression and PTSD. Psychiatr Danub. 2019;31:84-91.

31. Chwastiak LA, Rosenheck RA, Kazis LE. Utilization of primary care by veterans with psychiatric illness in the national department of veterans affairs health care system. J Gen Intern Med. 2008;23(11):1835-40.

32. Hetlevik $\varnothing$, Solheim M, Gjesdal S. Use of GP services by patients with schizophrenia:a national cross-sectional register-based study. BMC Health Serv Res. 2015;15:66.

\section{Publisher's Note}

Springer Nature remains neutral with regard to jurisdictional claims in published maps and institutional affiliations.

Ready to submit your research? Choose BMC and benefit from

- fast, convenient online submission

- thorough peer review by experienced researchers in your field

- rapid publication on acceptance

- support for research data, including large and complex data types

- gold Open Access which fosters wider collaboration and increased citations

- maximum visibility for your research: over 100M website views per year

At BMC, research is always in progress.

Learn more biomedcentral.com/submissions 